Article

\title{
Synthesis of $\gamma$-Nitro Aliphatic Methyl Esters Via Michael Additions Promoted by Microwave Irradiation
}

\section{Jaime Escalante * and Francisco D. Díaz-Coutiño}

Centro de Investigaciones Químicas, Universidad Autónoma del Estado de Morelos. Av. Universidad No. 1001, Col. Chamilpa, C.P. 62210 Cuernavaca, Mor., Mexico; Email: dadico@ciq.uaem.mx (FD.D-C.)

* Author to whom correspondence should be addressed; E-mail: jaime@ciq.uaem.mx.

Received: 5 February 2009; in revised form: 21 March 2009/ Accepted: 8 April 2009/ Published: 21 April 2009

\begin{abstract}
A simple and efficient protocol has been developed for the direct synthesis of $\gamma$ nitrobutyric acid methyl esters under microwave irradiation. This methodology reduces reaction times from days to minutes, compared to conventional conditions. Additionally, these conditions increased yields and provided cleaner reactions.
\end{abstract}

Keywords: Microwave irradiation; $\alpha, \beta$-Unsaturated; Michael additions; $\gamma$-Nitro aliphatic methyl esters; Catalysis.

\section{Introduction}

Microwave (MW) irradiation is widely used to promote chemical reactions and a number of reviews have advocated the use of MW technology in organic synthesis [1-2]. There are more than 3,000 documented examples of Microwave Assisted Organic Synthesis (MAOS) reported by both academic and industrial laboratories, which suggests that most chemical transformations can be carried out successfully under microwave conditions. The result of this has been a diverse range of chemical transformations, successfully performed through microwave irradiation, including cycloaddition, elimination, substitution and addition reactions [3-14]. Microwave-assisted heating under controlled conditions is an invaluable technology because it often dramatically reduces reactions times, typically from days or hours to minutes or even seconds [15-19]. The acceleration of reactions by MW exposure 
results from material-wave interactions leading to thermal effects connected to the intervention of "hot spots" (localized microscopic high temperatures) and specific (non-thermal) effects [20]. In the case of the specific (non-thermal) MW effects it has been found that reactions proceed with considerable lower yields under similar thermal conditions demonstrating that the effect of MW is evidently not purely thermal. These specific non-thermal effects of MW are increased when the polarity of a system is enhanced. In the Michael addition the rate-determining step consist in the nucleophilic addition on carbon-carbon double bond of $\alpha, \beta$-unsaturated carbonyl compound. One can expect important specific MW effects due to the enhancement of polarity of the system during the reaction progress, which is provided by ionic dissociation of the ions pairs from the ground state of the reaction towards the transition state, which is more polar due to the negative charge delocalization. The more important stabilization of the transition state by dipole-dipole electrostatic interactions with the electric field is therefore responsible for an enhancement of reactivity by a decrease of the activation energy [21,22].

The reaction of functionalized nitroalkanes with electrophiles such as Michael acceptors is one of the most exploited procedures for the formation of new carbon-carbon bonds [23-27]. The versatility of this reaction is due to the variety of Michael donors and Michael acceptors $(\alpha, \beta$-unsaturated compounds) that can be employed. The fact that the nitro functionality can easily be transformed into an amine, an oxime, a ketone, or a carboxylic acid, provides a wide range of synthetically interesting compounds [28-30]. Additionally, the carbon-carbon bond formation can potentially be made in a diastereo- or enantioselective fashion through the use of modern techniques applicable to asymmetric synthesis, affording optically active derivates.

As a part of one of our projects aimed at the development of biocatalysts for the resolution of racemic amino methyl esters [31], our research group has developed a procedure for the preparation of a series of nitro methyl esters $(3,5, \mathbf{8}$, and 11-13), derived from 1,4-addition of nitroalkanes ( 2 and 10) to methyl crotonate (1), methyl acrylate (4), and methyl methacrylate (7), and catalyzed by 1,8 diazabicyclo[5.4.0] undec-7-ene (DBU) [32] under microwave irradiation. The addition reactions were carried out in nitromethane or nitroethane in a monomode CEM Discover microwave apparatus, in a sealed system, in vessels rated for high pressure. In every case the experiments were performed on a 10 or $20 \mathrm{mmol}$ scale.

\section{Results and Discussion}

\subsection{Preparation of methyl 3-methyl-4-nitrobutanoate (3)}

In an initial study, the reaction between methyl crotonate (1), nitromethane (2), and DBU was carried out under the method described by Silverman (Scheme 1, Table 1, entry 1) [33], providing the $\gamma$-nitro aliphatic methyl ester 3 in $72 \%$ yield after a prolonged period of time (4,320 min). It is worth mentioning that the product was also obtained under conventional conditions $\left(70-75^{\circ} \mathrm{C}\right)$, albeit after a longer reaction time (Table 1, entry 2). Surprisingly, when the same reaction was performed under microwave irradiation, the reaction times decreased dramatically to $5 \mathrm{~min}$, see Table 1 (entry 3) and gave better yields ( $\geq 98 \%$ ). To assess the number of equivalents of DBU required in this reaction, we carried out experiments using 0.1, 0.05, and 0.01 equivalents of DBU in 5 min (Table 1, entries 4, 5, and 6), with 0.1 equivalents being identified as the optimal concentration for this reaction. The low 
yield in entry $6(0.01$ eq of DBU) could be overcome by increasing the reaction time to 20 min (Table 1 , entry $7, \geq 97 \%$ yield). In order to demonstrate the effect of microwaves on the 1,4-addition the reaction was carried out under conventional conditions $\left(70-75^{\circ} \mathrm{C}\right)$ with 0.1 equivalents of DBU for 5 min (Table 1, entry 8). In this case, we found no product. Therefore, the observed rate-acceleration using microwaves demonstrating that the effect of MW is evidently not purely thermal.

Scheme 1. Preparation of methyl 3-methyl-4-nitrobutanoate (3).<smiles>C/C=C/C(=O)OC</smiles>

1<smiles>C[N+](=O)[O-]</smiles>

2<smiles>COC(=O)C[C@H](C)C[N+](=O)[O-]</smiles>

3

Table 1. Effect of DBU on the 1,4-addition of nitromethane (2) to methyl crotonate (1).

\begin{tabular}{|c|c|c|c|c|c|}
\hline Entry & Eq. DBU & Power (W) & Temperature $\left({ }^{\mathbf{0}} \mathbf{C}\right)$ & Time (min) & Yield 3 (\%) \\
\hline 1 & 1.1 & - & r. t. & 4320 & 72 \\
2 & 1.1 & - & $70-75$ & 150 & $65^{a}$ \\
3 & 1.1 & 50 & $70-75$ & 5 & $\geq 98^{b}$ \\
4 & 0.1 & 50 & $70-75$ & 5 & $\geq 98^{b}$ \\
5 & 0.1 & - & $70-75$ & 5 & $0^{c}$ \\
6 & 0.05 & 50 & $70-75$ & 5 & $80^{c}$ \\
7 & 0.01 & 50 & $70-75$ & 5 & $10^{c}$ \\
8 & 0.05 & 50 & $70-75$ & 20 & $\geq 97^{c}$ \\
\hline
\end{tabular}

${ }^{a}$ Reaction was performed under conventional conditions and the yield was obtained after purification in column chromatography. ${ }^{b}$ Reaction was performed under microwave irradiation and the yield was obtained after product purification by column chromatography. ${ }^{c}$ Obtained by ${ }^{1} \mathrm{H}-\mathrm{NMR}$.

\subsection{Preparation of methyl 4-nitrobutanoate (5) and methyl 2-methyl-4-nitrobutanoate (8)}

We extended this protocol to the Michael addition of nitromethane (2) to methyl acrylate (4) and methyl methacrylate (7) (Scheme 2).

Scheme 2. Preparation of methyl 4-nitrobutanoate (5) and methyl 2-methyl-4-nitrobutanoate (8).<smiles>[R12][R4](=C)C</smiles><smiles>CCCCCCCCCCCCC</smiles><smiles>[R1]C(CC[N+](=O)[O-])C(=O)OC</smiles>

7: $\mathrm{R}_{1}=\mathrm{CH}_{3}$

2

5: $\mathrm{R}_{1}=\mathrm{H}$

8: $\mathrm{R}_{1}=\mathrm{CH}_{3}$

The addition of nitromethane (2) to methyl acrylate (4) provided compound 5 and one side product. TLC analysis of the reaction mixture after 30 min showed two products, the more polar product being 
the major component. After purification by column chromatography, the ${ }^{1} \mathrm{H}$ - and ${ }^{13} \mathrm{C}-\mathrm{NMR}$ analysis indicated that the less polar product corresponded to a double 1,4-addition product 6 (Figure 1), whereas the more polar component was the desired product 5, obtaned in $10 \%$ and $69 \%$ yield respectively. A proposed mechanism for the formation of dimeric product $\mathbf{6}$ is illustrated in Figure 2.

Figure 1. Double 1,4-addition product, compound 6.<smiles>COC(=O)CCC(CCC(=O)OC)[N+](=O)[O-]</smiles>

Figure 2. Proposed mechanism for the formation of the double 1,4-addition product 6.

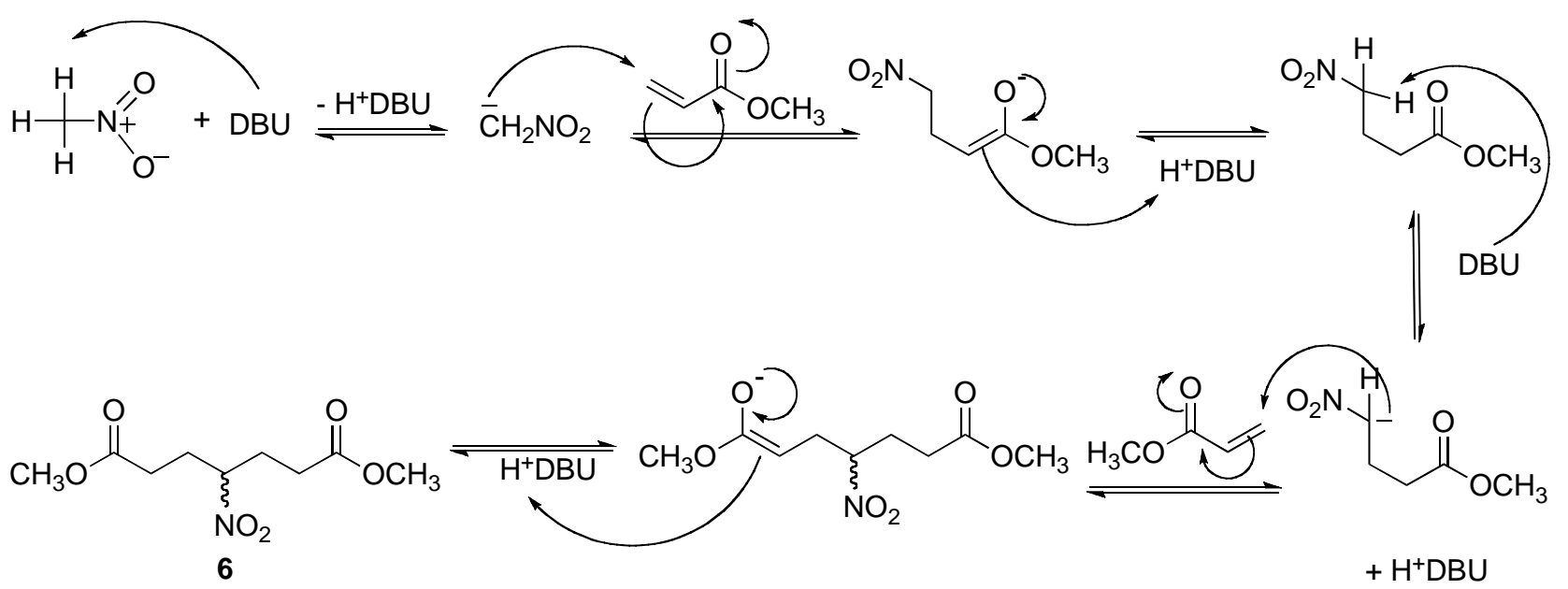

The addition of nitromethane (2) to methyl methacrylate (7) was carried out initially under conventional conditions in 4,320 $\mathrm{min}$ [33] (Table 2, entry 1). These conditions provided a mixture of products 8 and 9 (Figure 3 ) in 47 and $53 \%$ yields, respectively.

Figure 3. Double 1,4-addition product, compound 9.<smiles>COC(=O)[C@H](C)C[C@@H](C)C(=O)OC</smiles>

When the same reaction was performed under conventional conditions, the ${ }^{1} \mathrm{H}-\mathrm{NMR}$ analysis indicated a 27/73 ratio of the products $\mathbf{8 / 9}$ (Table 2, entry 2). In order to minimize the by-product 9 and to determine the effect of the microwaves in this process, the equivalents of DBU and the time were decreased to 0.1 eq and $5 \mathrm{~min}$, respectively (Table 2, entry 3). Under these reaction conditions an 8:9:7 ratio of 45:45:10 was obtained. This result suggests that a thermal effect of the microwaves is essential in the formation of product 9. In an effort to explore the specific (non-thermal) MW effect, we decided to change the base in this reaction, tetramethylguanidine (TMG, pKa 13.6) [34]. Interestingly, under MW irradiation the ratio of 8:9:7 was 72/28/0 (Table 2, entry 4). However, when the reaction was performed under conventional conditions, the ratio of 8:9:7 was 35/65/0 (Table 2, entry 5). This 
demonstrates that, in the Michael addition reaction, the formation of product 9 is due to a thermal effect, while the formation of product 8 can be explained by a specific (non-thermal) microwave effect $[20,21]$.

Table 2. Formation of 8 and 9 by 1,4-addition of nitromethane (2) to Methyl Methacrylate (7).

\begin{tabular}{|c|c|c|c|c|c|}
\hline Entry & Eq. Base & Power (W) & $\begin{array}{c}\text { Temperature } \\
\left.\mathbf{(}^{\mathbf{0}} \mathbf{C}\right)\end{array}$ & Time (min) & $\mathbf{8} / \mathbf{9} / \mathbf{7}(\mathbf{\%})^{a}$ \\
\hline 1 & $1.1 \mathrm{DBU}$ & - & r. t. & 4320 & $47 / 53 / 0$ \\
2 & $1.1 \mathrm{DBU}$ & - & $70-75$ & 5 & $27 / 73 / 0$ \\
3 & $0.1 \mathrm{DBU}$ & 50 & $70-75$ & 5 & $45 / 45 / 10$ \\
4 & $0.5 \mathrm{TMG}$ & 50 & $70-75$ & 20 & $72 / 28 / 0$ \\
5 & $0.5 \mathrm{TMG}$ & - & $70-75$ & 20 & $35 / 65 / 0$ \\
\hline
\end{tabular}

${ }^{a}$ Reaction was performed under microwave irradiation and the yield was obtained by ${ }^{1} \mathrm{H}$ NMR

2.3. Preparation of methyl 3-methy-4-nitropentanoate (11), methyl 4-nitropentanoate (12), and methyl 2-methy-4-nitropentanoate (13)

To expand the generality of this methodology, we also carried out the Michael addition of nitroethane (10) to the $\alpha, \beta$-unsaturated esters $\mathbf{1}, \mathbf{4}$, and 7 under microwave heating (Scheme 3 ).

Scheme 3. Preparation of methyl 3-methy-4-nitropentanoate (11), methyl 4nitropentanoate (12), and methyl 2-methyl-4-nitropentanoate (13).

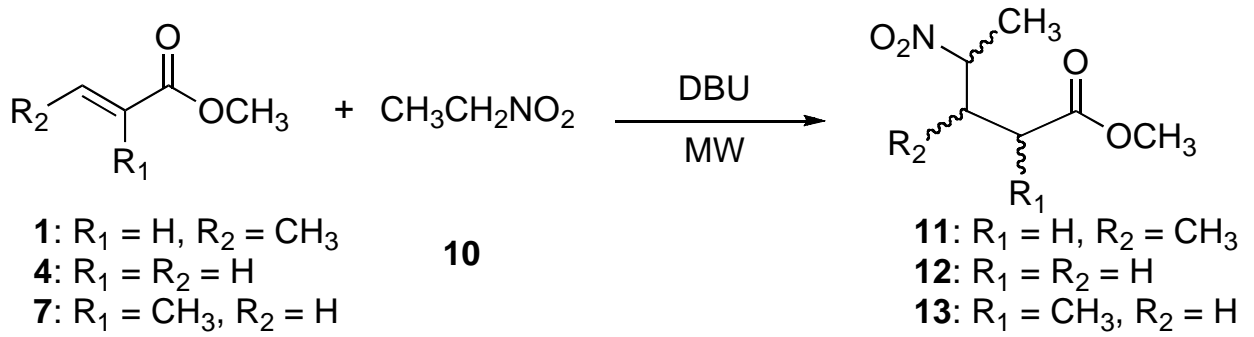

First, the addition of nitroethane (10) to methyl crotonate (1) was performed under microwave irradiation with 0.05 eq of DBU for 5 min (Table 3, entry 1). This provided the ester 11 in excellent yield as an inseparable mixture of isomers with no diastereomeric excess (50:50).

The addition of nitroethane (10) to methyl acrylate (4) was carried out for 5 min (Table 3, entry 2). The product 12 was obtained in essentially quantitative yields. Finally, we found that the addition of nitroethane (10) to methyl methacrylate (7) under microwave irradiation for 5 min (Table 3, entry 3) affords the ester 13, which was isolated as a 78:22 diastereomeric mixture (by ${ }^{1} \mathrm{H}-\mathrm{NMR}$ analysis). In this case, the esters were separated by column chromatography without assignment of the absolute configuration. 
Table 3. Addition of nitroethane (10) to different methyl acrylates $(\mathbf{1}, \mathbf{4}$, and 7).

\begin{tabular}{|c|c|c|c|c|c|c|}
\hline Entry & $\begin{array}{c}\text { Methyl } \\
\text { acrylates }\end{array}$ & Eq. DBU & Power (W) & Temperature $\left({ }^{\mathbf{o}} \mathbf{C}\right)$ & Time (min) & Product (\%) ${ }^{a}$ \\
\hline 1 & $\mathbf{1}$ & 0.05 & 50 & $70-75$ & 5 & $\mathbf{1 1}(98)^{b}$ \\
2 & $\mathbf{4}$ & 0.05 & 50 & $70-75$ & 5 & $\mathbf{1 2}(>99)^{c}$ \\
3 & $\mathbf{7}$ & 0.05 & 50 & $70-75$ & 5 & $\mathbf{1 3}(83)^{b}$ \\
\hline
\end{tabular}

${ }^{a}$ Yield after their purification by column chromatography. ${ }^{b}$ Diastereomeric ratio was obtained by ${ }^{1} \mathrm{H}-\mathrm{NMR} .{ }^{c}$ When the reaction is carried out for 4,320 min without microwave irradiation the yield was only $44 \%$.

\section{Conclusions}

In summary, a practical and high-yielding methodology to synthesize $\gamma$-nitrobutyric acid methyl esters under microwave irradiation has been developed. With this protocol the reaction times are significantly shortened, in comparison with conventional conditions. The extension of this methodology to other $\alpha, \beta$-unsaturated compounds has proven successful and this work is currently under further investigation.

\section{Experimental}

\subsection{General}

${ }^{1} \mathrm{H}$ - and ${ }^{13} \mathrm{C}$-NMR spectra were obtained in $\mathrm{CDCl}_{3}$ solutions with TMS as internal standard on Varian Gemini 200 or Inova $400 \mathrm{MHz}$ spectrometers. Reactions were performed in sealed vessels in a monomode microwave CEM Discover apparatus and the temperature was evaluated by infrared. Methyl crotonate (1), nitromethane (2), methyl acrylate (4), methyl methacrylate (7), nitroethane (10), DBU, and TMG were purchased from Aldrich and used without further purification.

\subsection{General procedure: Synthesis of methyl 4-nitro alkyl esters via microwave irradiation}

A solution of $\alpha, \beta$-unsaturated ester $(1,4,7)$ and the corresponding nitroalkane (2 or 10) in DBU or TMG were added to a $10-\mathrm{mL}$ glass microwave reaction vessel containing a stir bar. The reaction vessel was sealed with a cap and then placed into the microwave cavity. The microwave unit was programmed to heat the reaction mixture to the desired temperature. After the reaction was completed and the vessel was cooled to below $50{ }^{\circ} \mathrm{C}$ using a flow of compressed air, the crude material was purified by column chromatography to give the product.

Methyl 3-methyl-4-nitrobutanoate (3): Prepared from methyl crotonate (1, $10 \mathrm{mmol})$, nitromethane (2, $25 \mathrm{mmol})$ and $\mathrm{DBU}(0.1 \mathrm{mmol})$. The microwave unit was programmed to $70-75^{\circ} \mathrm{C}$ and a power of 50 Watts for $5 \mathrm{~min}$. After the reaction was completed, the vessel was cooled to below $50{ }^{\circ} \mathrm{C}$ using a flow of compressed air. The crude material was purified by column chromatography (hexane-ethyl acetate 
8:2), afforded the product $3(\geq 98 \%)$ as a colorless liquid. ${ }^{1} \mathrm{H}-\mathrm{NMR}\left(200 \mathrm{MHz}, \mathrm{CDCl}_{3}\right) \delta 1.11(\mathrm{~d}, J=$ $7.0 \mathrm{~Hz}, 3 \mathrm{H}), 2.42(\mathrm{dd}, J=6.8,7.0 \mathrm{~Hz}, 2 \mathrm{H}), 2.68-2.90(\mathrm{~m}, 1 \mathrm{H}), 3.70$ (s, 3H), 4.35 (dd, $J=12.1,6.9 \mathrm{~Hz}$, 1H), $4.49(\mathrm{dd}, 12.1,6.2 \mathrm{~Hz}, 1 \mathrm{H}) ;{ }^{13} \mathrm{C}-\mathrm{NMR}\left(50 \mathrm{MHz}, \mathrm{CDCl}_{3}\right) \delta 17.6,29.7,37.9,52.1,80.4,171.8$; HRMS (FAB+): calcd for $[\mathrm{M}+\mathrm{H}]^{+} \mathrm{C}_{6} \mathrm{H}_{12} \mathrm{NO}_{4}$ : 162.0766; found: 162.0779 .

Methyl 4-nitrobutanoate (5) and dimethyl 4-nitroheptanedioate (6): According with the general procedure, methyl acrylate $(4,10 \mathrm{mmol})$, nitromethane $(2,25 \mathrm{mmol})$ and DBU $(0.05 \mathrm{mmol})$ were heated at $70-75{ }^{\circ} \mathrm{C}$ with a power of 25 Watts for $0.5 \mathrm{~h}$. The crude material was purified by column chromatography (hexane-ethyl acetate 95:5) afforded 5 (69\%) and $\mathbf{6}(10 \%)$ as a colorless liquid. Compound 5: ${ }^{1} \mathrm{H}-\mathrm{NMR}\left(200 \mathrm{MHz}, \mathrm{CDCl}_{3}\right) \delta$ 2.04-2.33 (m, 4H), 2.36-2.49 (m, 2H), $3.69(\mathrm{~s}, 3 \mathrm{H}) ;{ }^{13} \mathrm{C}$ NMR $\left(50 \mathrm{MHz}, \mathrm{CDCl}_{3}\right) \delta 28.86,30.10,52.20,86.77,172.32 ; \mathrm{MS}_{-} \mathrm{EI}^{+}(\mathrm{m} / \mathrm{z}, \%): 116(\mathrm{M}-\mathrm{OMe})$. Compound 6: ${ }^{1} \mathrm{H}-\mathrm{NMR}\left(200 \mathrm{MHz} \mathrm{CDCl}_{3}\right) \delta 2.20-2.38(\mathrm{~m}, 9 \mathrm{H}), 3.69(\mathrm{~s}, 6 \mathrm{H}) ;{ }^{13} \mathrm{C}-\mathrm{NMR}(50 \mathrm{MHz}$, $\left.\mathrm{CDCl}_{3}\right) \delta 28.63,30.40,52.24,91.96,172.20 ; \mathrm{MS}_{-} \mathrm{EI}^{+}$(m/z, \%): 202 (M-OMe).

Methyl 2-methyl-4-nitrobutanoate (8) and dimethyl 2,6-dimethyl-4-nitroheptanedioate (9): Prepared from methyl methacrylate $(7,20 \mathrm{mmol})$, nitromethane $(2,25 \mathrm{mmol})$ and TMG $(0.5 \mathrm{mmol})$. The Microwave unit was programmed to $70-75^{\circ} \mathrm{C}$ and a power of 25 Watts for $20 \mathrm{~min}$. After the reaction was completed, the vessel was cooled to below $50{ }^{\circ} \mathrm{C}$ using a flow of compressed air. The crude material was purified by column chromatography (hexane-ethyl acetate 98:2), afforded the product 8 (72\%) and 9 (28\%) as a colorless liquid. Compound 8: ${ }^{1} \mathrm{H}-\mathrm{NMR}\left(200 \mathrm{MHz}, \mathrm{CDCl}_{3}\right) \delta 1.25(\mathrm{~d}, J=7.0$ $\mathrm{Hz}, 3 \mathrm{H}), 2.0-2.43(\mathrm{~m}, 2 \mathrm{H}), 2.50-2.70(\mathrm{~m}, 1 \mathrm{H}), 3.71(\mathrm{~s}, 3 \mathrm{H}), 4.46(\mathrm{t}, J=7.0 \mathrm{~Hz}, 2 \mathrm{H},) ;{ }^{13} \mathrm{C}-\mathrm{NMR}(50$ $\left.\mathrm{MHz}, \mathrm{CDCl}_{3}\right) \delta 17.4,30.7,36.6,52.2,73.5,175.3$; HRMS $(\mathrm{FAB}+)$ : calcd for $[\mathrm{M}+\mathrm{H}]^{+} \mathrm{C}_{6} \mathrm{H}_{12} \mathrm{NO}_{4}$ : 162.0766; found: 162.0863. Compound 9: ${ }^{1} \mathrm{H}-\mathrm{NMR}\left(200 \mathrm{MHz}, \mathrm{CDCl}_{3}\right) \delta 1.20(\mathrm{~d}, J=5.80 \mathrm{~Hz}, 3 \mathrm{H})$, $1.24(\mathrm{~d}, J=5.80 \mathrm{~Hz}, 3 \mathrm{H}), 1.74-1.93(\mathrm{~m}, 2 \mathrm{H}), 2.0-2.11(\mathrm{~m}, 2 \mathrm{H}), 2.35-2.53(\mathrm{~m}, 2 \mathrm{H}), 3.69(\mathrm{~s}, 3 \mathrm{H}), 3.71$ (s, 3H), 4.57-4.74 (m, $J=4.4 \mathrm{~Hz}, 1 \mathrm{H}) ;{ }^{13} \mathrm{C}-\mathrm{NMR}\left(50 \mathrm{MHz}, \mathrm{CDCl}_{3}\right) \delta$ 17.96, 36.29,37.59, 52.08, 85.41, 175.36; HRMS (FAB+): calcd for [M+H] ${ }^{+} \mathrm{C}_{11} \mathrm{H}_{20} \mathrm{NO}_{6}$ : 262.1246; found: 262.1270 .

Methyl 3-methy-4-nitropentanoate (11): Prepared from methyl crotonate (1, $10 \mathrm{mmol})$, nitroethane (10, $25 \mathrm{mmol})$ and DBU $(0.05 \mathrm{mmol})$. The microwave unit was programmed to $70-75^{\circ} \mathrm{C}$ and a power of 50 Watts for 5 min to afford a 1:1 mixture of diastereomeric compounds, which were not separable. The crude material was purified by column chromatography (hexane-ethyl acetate 9:1), afforded the product $11(98 \%)$ as a colorless liquid. ${ }^{1} \mathrm{H}-\mathrm{NMR}\left(200 \mathrm{MHz}, \mathrm{CDCl}_{3}\right) \delta 1.03(\mathrm{dd}, J=1.2,1.6 \mathrm{~Hz}, 3 \mathrm{H})$, $1.53(\mathrm{dd}, J=3.6,3.6 \mathrm{~Hz}, 3 \mathrm{H}) 2.18-2.30(\mathrm{~m}, 1 \mathrm{H}), 2.35-2.43(\mathrm{~m}, 1 \mathrm{H}), 2.46-2.66(\mathrm{~m}, 1 \mathrm{H}), 3.70(\mathrm{~s}, 3 \mathrm{H})$, 4.53-4.70 (m, 1H); ${ }^{13} \mathrm{C}-\mathrm{NMR}\left(50 \mathrm{MHz}, \mathrm{CDCl}_{3}\right) \delta 15.64,15.81,16.55,34.57,34.69,37.30,37.54$, 52.08, 86.57, 86.62, 171.97, 172.17; HRMS (FAB+): calcd for $[\mathrm{M}+\mathrm{H}]^{+} \mathrm{C}_{11} \mathrm{H}_{20} \mathrm{NO}_{6}$ : 176.0878; found: 176.0945 .

Methyl 4-nitropentanoate (12): Prepared from methyl acrylate (7, $20 \mathrm{mmol})$, nitroethane (10, 25 $\mathrm{mmol})$ and DBU $(0.05 \mathrm{mmol})$. The microwave unit was programmed to $70-75{ }^{\circ} \mathrm{C}$ and a power of 50 Watts for $5 \mathrm{~min}$. After the reaction was completed, the vessel was cooled to below $50{ }^{\circ} \mathrm{C}$ using a flow of compressed air. The crude material was purified by column chromatography (hexane-ethyl acetate 80:20), afforded the product 12 (>99\%) as a colorless liquid. ${ }^{1} \mathrm{H}-\mathrm{NMR}\left(400 \mathrm{MHz}, \mathrm{CDCl}_{3}\right) \delta 1.57(\mathrm{~d}, J$ 
$=6.8 \mathrm{~Hz}, 3 \mathrm{H}), 2.06-2.16(\mathrm{~m}, 1 \mathrm{H}), 2.23-2.34(\mathrm{~m}, 1 \mathrm{H}), 2.35-2.47(\mathrm{~m}, 2 \mathrm{H}), 3.70(\mathrm{~s}, 3 \mathrm{H}), 4.62-4.71(\mathrm{~m}$, $1 \mathrm{H}) ;{ }^{13} \mathrm{C}-\mathrm{NMR}\left(100 \mathrm{MHz}, \mathrm{CDCl}_{3}\right) \delta 19.2,29.7,29.8,51.8,82.3,172.3$; HRMS (FAB+): calcd for $[\mathrm{M}+\mathrm{H}]^{+} \mathrm{C}_{6} \mathrm{H}_{12} \mathrm{NO}_{4}$ : 162.0766; found: 162.0768 .

Methyl 2-methy-4-nitropentanoate (13): Prepared from methyl methacrylate (7, $20 \mathrm{mmol})$, nitroethane $(\mathbf{1 0}, 25 \mathrm{mmol})$ and DBU $(0.05 \mathrm{mmol})$. The microwave unit was programmed to $70-75{ }^{\circ} \mathrm{C}$ and a power of 50 Watts for $5 \mathrm{~min}$. After the reaction was completed, the vessel was cooled to below $50{ }^{\circ} \mathrm{C}$ using a flow of compressed air. The crude material was purified by column chromatography (hexane 100\%), afforded a 72:22 diastereomeric mixture of $\mathbf{1 3}$ as a colorless liquid. Less polar compound 13: ${ }^{1} \mathrm{H}-\mathrm{NMR}$ $\left(200 \mathrm{MHz} \mathrm{CDCl}_{3}\right) \delta 1.21(\mathrm{~d}, J=7.4 \mathrm{~Hz}, 3 \mathrm{H}), 1.55(\mathrm{~d}, J=6.6 \mathrm{~Hz}, 3 \mathrm{H}) 2.02-2.09(\mathrm{~m}, 2 \mathrm{H}), 2.39-2.57$ $(\mathrm{m}, 1 \mathrm{H}), 3.71(\mathrm{~s}, 3 \mathrm{H}), 4.56-4.73(\mathrm{~m}, J=6.8 \mathrm{~Hz}, 1 \mathrm{H}) ;{ }^{13} \mathrm{C}-\mathrm{NMR}\left(50 \mathrm{MHz}, \mathrm{CDCl}_{3}\right) \delta 18.17,20.17$, 36.48, 38.70, 52.13, 82.10, 175.74. More polar compound 13: ${ }^{1} \mathrm{H}-\mathrm{NMR}\left(200 \mathrm{MHz}, \mathrm{CDCl}_{3}\right) \delta 1.24(\mathrm{~d}, J$ $=7.0 \mathrm{~Hz}, 3 \mathrm{H}), 1.56(\mathrm{~d}, J=6.8 \mathrm{~Hz}, 3 \mathrm{H}) 1.75-1.88(\mathrm{~m}, 1 \mathrm{H}), 2.38-2.55(\mathrm{~m}, 2 \mathrm{H}), 3.70(\mathrm{~s}, 3 \mathrm{H}), 4.56-4.75$ $(\mathrm{m}, J=6.6 \mathrm{~Hz}, 1 \mathrm{H}) ;{ }^{13} \mathrm{C}-\mathrm{NMR}\left(50 \mathrm{MHz}, \mathrm{CDCl}_{3}\right) \delta 17.10,19.72,36.44,38.38,52.18,81.27,175.47$; MS-EI ${ }^{+}(\mathrm{m} / \mathrm{z}, \%): 144(\mathrm{M}-\mathrm{OMe})$.

\section{Acknowledgements}

We are grateful to the CONACYT for financial support (Project No. 48356-Q). Daniel DíazCoutiño thanks CONACyT for a scholarship. We are grateful to Dr. Ismael León Rivera for technical support and to Grace Vanier, Saúl Jaime-Figueroa, and Robert Greenhouse for many important observations.

\section{References and Notes}

1. Loupy, A.; Petit, A.; Hamelin, J.; Texier-Boullet, F.; Jacquault, P.; Mathe, D. New solvent-free organic synthesis using focused microwaves. Synthesis 1998, 9, 1213-1234.

2. Caddick, S. Microwave assisted organic reactions. Tetrahedron 1995, 51, 10403-10432.

3. Kappe, C.O. Controlled Microwave Heating in Modern Organic Synthesis. Angew. Chem., Int. Ed. 2004, 43, 6250-6284.

4. Lidström, P.; Tierney, J.; Wathey, B.; Westman, J. Microwave assisted organic synthesis. Tetrahedron 2001, 57, 9225-9283.

5. Escalante, J.; Carrillo-Morales, M.; Linzaga, I. Michael Additions of Amines to Methyl Acrylates Promoted by Microwave Irradiation. Molecules 2008, 13, 340-347.

6. Larhed, M.; Hallberg, A. Microwave-promoted palladium catalyzed coupling reactions. J. Org. Chem. 1996, 61, 9582-9584.

7. Garg, N.; Larhed, M.; Hallberg, A. Heck arylation of 1,2-cyclohexanedione and 2-ethoxy-2cyclohexenone. J. Org. Chem. 1998, 63, 4158-4162.

8. Kabalka, G.W.; Wang, L.; Namboodiri, V.; Pagni, R.M. Rapid microwave-enhanced, solventless Sonogashira coupling on alumina. Tetrahedron Lett. 2000, 41, 5151-5154.

9. Blettner, C.G.; Köning, W.A.; Stenzel, W.; Schotten, T. Microwave-assisted aqueous Suzuki cross-coupling reactions. J. Org. Chem. 1999, 64, 3885-3890. 
10. Larhed, M. Hoshino, M.; Hadida, S.; Curran, D.P.; Hallberg, A. Rapid fluorous Stille coupling reactions conducted under microwave irradiation. J. Org. Chem. 1997, 62, 5583-5587.

11. Maleczka, R.E. Lavis, J.M.; Clark, D.H.; Gallagher, W.P. Microwave-assisted one-pot hydrostannylation/Stille couplings. Org. Lett. 2000, 2, 3655-3658.

12. Loupy, A., Ed. Microwaves in Organic Synthesis, 2nd. Ed. Wiley-VCH: Weinheim, Germany, 2006; Vol. 1, pp. 1-56.

13. Kappe, C.; Stadler, A.; Mannhold, R.; Kubinyi, H.; Folkers, G. Methods and Principles in Medicinal Chemistry: Microwaves in Organic and Medicinal Chemistry, Volume 25. Wiley-VCH: Weinheim, Germany, 2005; pp. 9-24.

14. Hayes, B.L.; Microwave Synthesis: Chemistry at the Speed of Light. CEM Publishing: Mattehews, N.C., USA, 2002; pp. 11-26.

15. Kappe, O.C.; Dallinger, D. The impact of microwave synthesis on drug discovery. Nature Reviews 2006, 5, 51-64.

16. Mavandadi, F.; Lidströn, P. Microwave-Assisted Chemistry in Drug Discovery. Current Topics in Medicinal Chemistry 2004, 4, 773-792.

17. Shipe, W.D.; Wolkenberg, S.E.; Lidsley, C.W. Accelerating lead development by microwaveenhanced medicinal chemistry. Drug Discovery Today: Technologies 2005, 2, 155-161.

18. Mavandadi, F.; Piotti, A. The impact of microwave-assisted organic synthesis in drug discovery. DDT-Reviews 2006, 11, 165-174.

19. Kappe, O.C. Microwave dielectric heating in synthetic organic chemistry. Chem. Soc. Rev. 2008, 37, 1127-1139.

20. Perreux, L.; Loupy, A. A tentative rationalization of microwave effects in organic synthesis according to the reaction medium, and mechanistic considerations. Tetrahedron 2001, 57, 91999223.

21. Dandia, A.; Sati, M.; Arya, K.; Sharma, R.; Loupy, A. Facile one pot microwave induced solventfree synthesis and antifungal, Antitubercular screening of spiro [1,5]-benzothiazepin2,3'[3'H]indol-2[1'H]-ones. Chem. Pharm. Bull. 2003, 51, 1137-1141.

22. Dandia, A.; Sati, M.; Arya, K.; Loupy, A. One-pot dry media synthesis of new tetracyclic 1,5benzothiazepines under microwave activation. Heterocycles 2003, 60, 563- 569.

23. Chasar, D.W. An improved Synthesis of 4-nitrocarboxilic Acid Esters. Synthesis Communications $1982,841-842$.

24. Ballini, R.; Petrini, M. Facile and Inexpensive Synthesis of 4-Oxoalkanoic Acids from Primary Nitroalkanes and Acrolein. Synthesis 1986, 1024-1026.

25. Chetia, A.; Saikia, Ch. J.; Lekhok, K.C.; Boruah, R.C. A facile synthesis of 1,7-dicarbonyl compounds via three-component Michael addition reactions. Tetrahedron Letters 2004, 45, 26492651.

26. Chamakh, A.; M'hirsi, M.; Villieras, J.; Lebreton, J.; Amri, H. A Simplified Route to (E)-2Alkylidene-1,4-diketones. Synthesis 2000, 295-299.

27. Ballini, R.; Barboni, L.; Fiorini, D.; Palmieri, A.; Petrini, M. Nitro compounds as useful reagents for the synthesis of dicarbonyl derivates. Arkivoc 2006, (vi), 127-152.

28. Tucker, J.A.; Clayton, T.L.; Mordas, D.M. Alkylation of Ketene Silyl Acetals with Nitroolefins Mediated by Sterically Encumbered Lewis Acids. J. Org. Chem. 1997, 62, 4370-4375. 
29. Busch, K.; Groth, U.M.; Kühnle, W.; Schöllkopf, U. Asymmetric Synthesis of Diastereomerically and Enantiomerically Pure $\alpha$-Amino- $\gamma$-Nitro Carboxylic Esters via Michael Addition of the Titanated Bislactim Ether of Cyclo (-L-Val-Gly-) to Nitroolefines. Tetrahedron 1992, 48, $5607-$ 5618.

30. Hayashi, T.; Senda, T.; Ogasawara, M. Rhodium-Catalized Asymmetric Conjugate Addition of Organoboronic Acids to Nitroalkenenes. J. Am. Chem. Soc. 2000, 122, 10716-10717.

31. Flores-Sánchez, P.; Escalante, J.; Castillo, E. Enzymatic resolution of $N$-protected- $\beta^{3}$-amino methyl esters, using lipase B from Candida antarctica. Tetrahedron-Asymmetry 2005, 16, 629-634.

32. Phiashivongsa, P.; Samoshin, V.V.; Gross, P.H. Henry condensations with 4,6-Obenzylidenylated and non-protected $D$-glucose and $L$-fucose via DBU-catalysis. Tetrahedron Lett. 2003, 44, 5495-5498.

33. Andruszkiewicz, R.; Silverman, R.; A convenient synthesis of 3-alkyl-4-aminobutanoic acids. Synthesis 1989, 19 , 953-955.

34. http://www.chem.wisc.edu/areas/reich/pkatable/index.htm. (accessed March 30, 2009).

Sample Availability: Samples are available from the authors.

(C) 2009 by the authors; licensee Molecular Diversity Preservation International, Basel, Switzerland. This article is an open-access article distributed under the terms and conditions of the Creative Commons Attribution license (http://creativecommons.org/licenses/by/3.0/). 